\title{
A nationwide production analysis of state park attendance in the United States
}

\author{
Christos Siderelis $^{\mathrm{a}, *}$, Roger L. Moore ${ }^{\mathrm{a}}$, Yu-Fai Leung ${ }^{\mathrm{a}}$, Jordan W. Smith ${ }^{\mathrm{b}}$ \\ a Department of Parks, Recreation and Tourism Management, North Carolina State University, USA \\ ${ }^{\mathrm{b}}$ Department of Forestry and Natural Resources, Purdue University, USA
}

\section{A R T I C L E I N F O}

\section{Article history:}

Received 3 February 2011

Received in revised form

16 August 2011

Accepted 7 January 2012

Available online

\section{Keywords:}

Outdoor recreation

Production

State parks

Recreation economics

Recreation planning

\begin{abstract}
A B S T R A C T
This study examined the production of U.S. states' park visits from 1984 to 2010 by state. In specifying the production equation in terms of the influences of the states' parklands, labor, and capital investments on the annual attendances, we found that state governments will experience an ongoing need for more labor to maintain their parklands if attendance is to increase in the future. Results also indicated that more capital expenditures are not likely to increase park utilization rates. Post-estimation procedures involved the application of the response residuals to identify the capacity utilization rates of the states' park systems over the past 27 years. Past utilization rates revealed operators met or exceeded capacity utilization expectations from 1984 through 1990 . However, beginning in 1991, the annual mean utilization rate for the nation's supply of states' parks signaled a trend toward excess capacity. Our forecast revealed the mean utilizations over the next three years will vary between $90 \%$ and $95 \%$. Post-estimation procedures also examined the relationship between state park management orientations (towards either public-lands preservation or recreational development) and projected annual capacity utilization rates. Results indicate that the quantity of added facilities to broaden their appeal to the public (i.e., a recreation orientation) was not important in explaining utilization capacities. However, an orientation toward publiclands preservation related significantly to greater utilization rates. In our view, the public will continue to accept current cost structures for continued operations of the states' parks on the compelling need for access to outdoor recreation to contribute to the visitor well-being.
\end{abstract}

(c) 2012 Elsevier Ltd. All rights reserved.

\section{Introduction}

This study focuses on state park systems in the United States. The states' parks are pivotal in the national effort to supply adequate outdoor recreation opportunities through their provision and administration of parklands (Landrum, 2004). The states' parks have evolved from their traditional purposes of acquiring scenic tracts of lands and opening them to public access for outdoor recreation with the primary aim of protecting natural resources and providing outdoor recreation opportunities to also providing restrooms, picnic tables, campsites, and other facilities. When we speak of providing outdoor recreation opportunities, we mean simply the consumer's access to a state park where the consumer may engage in various outdoor activities. In fact, any person can be a park consumer if that person pays all the necessary charges, if any, for park access and consumes the services. By performing their traditional roles of protecting natural resources and providing outdoor recreation opportunities, state parks contribute to public

\footnotetext{
* Correspondence author. Department of Parks, Recreation and Tourism Management, North Carolina State University, 4008 Biltmore Hall, Box 8004, Raleigh, NC 27695-8004, USA. Tel.: +1 919513 1700; fax: +1 9195153687.

E-mail address: chris_siderelis@ncsu.edu (C. Siderelis).
}

well-being by offering accessible opportunities that contribute to recreationists' physical health and mental well-being (Walls et al., 2009). During FY 2010, state parks attracted 717 million combined visits by residents and non-residents.

Despite the importance of the states' parks to the national supply of outdoor recreation opportunities, there are few published longitudinal studies about levels of consumption in terms of their production capabilities. Strauss's (1975) study of the production of recreation visits and average operating costs of the Pennsylvania park system is one. We are unaware of published research efforts that have attempted to examine the production processes and the capacity utilizations of the 50 states' park systems with cross-sectional and longitudinal data, or efforts that have applied aspects of management orientations to the consumption of services from the states' systems. Consumption refers to the quantity of annual attendance at a specific level of recreation supply and price.

\subsection{Problem}

Annual attendance is the technical measure of the quantity of visits to the state's parks at existing prices. We view a visit as consisting of a consumer with utility $U(x, Y)$ where $x$ is the single output 
of recreation experiences from the visit and $Y$ is the factor inputs (e.g., capital and labor) in the production of outdoor recreation opportunities. Operating in the best welfare of the consumer in supplying recreation opportunities, the operator solves the utility problem, max $U(x, Y)$, such that, the operator produces outdoor recreation by substituting into the consumer's utility the relationship, $x=f(Y)$. The function $f$ is homogenous, exhibiting returns to scale and continuously declining average total costs as state park visits increase and appears as an argument in the equation because the input prices are variable. The consideration of many visits does not alter the form of this problem. The importance of the solution is that it implies an operator will employ factor inputs to produce outdoor recreation until the consumer's marginal utility equals the marginal disutility of providing additional outdoor recreation opportunities. To this end, the operator attempts to satisfy that objective by lowering the average total cost in the long-run and by appropriating more inputs until annual attendance increases to an optimum quantity at the current price that consumers are able to pay for park access and facility use. The production process therefore requires that the consumer's demand for park access equal this equilibrium price at the consumer's fixed utility and a tax subsidy, as being preferable to not having the state park at all (Grandy, 2009).

Operators attempting to manage production with efficiencies often seen in the private sector incur perpetual losses at any price above an equilibrium price because the average total cost is always greater than the marginal cost, thus requiring state appropriations (Phaneuf and Smith, 2004). A primary reason for this is that the production of outdoor recreation is beset by distributional equity issues, motivated typically by a fairness doctrine, in terms of the geographically dispersion of a state's parks and consideration of the underlying economics of localities when distributing state tax revenues for outdoor recreation to the parks (Loomis and Walsh, 1997). All this implies is that the need to break even financially is not a necessary condition of park operation because the demand will always be everywhere below the average cost of operations at any breakeven price. In adopting this perspective, there are no assurances that operators will select the least costly combinations of factor inputs for outdoor recreation as production efficiencies warrant (Newcomer, 2007). Instead, operators make do with legislative appropriations and fixed quantities of inputs for the fiscal year and, in turn, execute the necessary adjustments in the production processes, which may include deferring maintenance, reducing visitor services and enforcement, and not necessarily increasing the prices that they charge to visitors for services or the rental of facilities.

\subsection{Study objective}

Our motivation for undertaking this production analysis of the states' parks is a societal one. We address the extent to which the operators can expand the capacity utilization of the states' parks without altering the quantity of the factor inputs. This analysis requires the estimation and prediction of both the annual attendances from the specified production model and the residual quantities, if any, of attendance. We attribute the magnitudes of the residuals to the operators' management practices that involve varying the compositions of the factor inputs and a symmetrical measurement error.

We acknowledge that the states' parks and their management systems are not autonomous entities functioning without knowledge of the resources and objectives in other states when making allocation decisions of production inputs in their attempts to maximize public utilization of parks to their capacities. We would not expect to find similar patterns of annual attendance in states with large proportions of federal lands, such as Utah, Nevada, and Idaho, as we would in states like Kentucky, Illinois, and Iowa, where state parks' services fulfill a larger proportion of the area's consumption of outdoor recreation. In this regard, Davis (2008) profiled the public land holding of states in an attempt to describe this diversity between and within the states' public land systems. Davis grouped the states' public land portfolios based on three broad objectives-preservation, resource extraction, and recreation-that appear in varying degrees in the state agencies' enabling legislation and mission statements and were reflected in policy decisions. A preservation-oriented focus is directed toward the need "to preserve and protect native ecosystems, natural landscapes, and biodiversity in general." An extraction orientation focuses on natural resource commodities, while a recreation orientation addresses the need "to manage public lands by providing passive and active recreation opportunities to the public and to bolster tourism as a form of economic development" (Davis, 2008, p. 3). In this regard, Landrum (2004) notes increased capital investments by operators in (a) golf courses, (b) resorts, (c) upgrading campsites, (d) snowmaking machines for skiing, (e) mountain-biking trails, (f) aquatic facilities, and (g) marinas, as well as other visitor services intended to broaden public appeal. Apparently, operators are increasing the suite of outdoor recreation opportunities they provide with the aim of generating additional revenues. In fact, over the past decade in real dollars (i.e., deflated with the consumer's price index to 2009 to remove the systematic bias of inflation) the year-over-year changes in park-generated revenues from such excludable goods was $3.1 \%$ ( $S D=8.4 \%$ ) (Siderelis and Moore, 2009). Additionally, state tax transfers for parks have continued to decline while annual attendance remains relatively flat at $740 \mathrm{M}$ (Siderelis et al., 2011). These findings have two important implications for this study's examination of capacity utilization and the nation's supply of states' parks. First, operators struggling with ever increasing operating and capital expenditures would be better off in the long-term producing additional outdoor recreation opportunities and should consider (or continue) relying on fees and charges in generating revenue in order to fund future services. Second, those systems collecting fees do so successfully, irrespective of their residual performances, apparently with minimal displacement of visitors from the states' parks at which operators collected fees.

The impetus for examining the capacity utilization of the states' park systems was the deteriorating economic outlook that began in FY 2008 coupled with that fact that the states' systems have historically been dependent on legislative appropriations and aid from nonprofit organizations. Since then, operators have been dealing with the question of how they might address the acute budgetary pressures their state governments face while attempting to assure services are in line with visitor preferences. Different examples of operator efforts to respond to the states' tax revenue shortfalls and to manage production schedules have been documented by the National Association of State Park Directors (NASPD, 2010). These include:

- imposing or increasing admission fees and charges on excludable goods and services;

- outsourcing services and facility operations to private vendors;

- limiting hours of operation and even temporarily or permanently closing parks (e.g., California officials report that a quarter, 70, of that state's parks are slated to close in 2012);

- ignoring backlogs in maintenance, thereby impacting the natural environment and possibly creating safety issues for visitors and increased liability exposure; and

- instituting hiring freezes and cuts to training budgets that inhibit leadership development and adoption of best management practices.

\subsection{Research questions}

This nation wide production analysis relative to the factor inputs employed by operators over 27 years does not result in absolute 
predictions about future production capabilities. Instead, the analysis provides an understanding of the utilization of the states' parks by consumers. We assess how much variations in the factor inputs can explain past attendance to forma clearer understanding of how the inputs might influence the production of outdoor recreation in the future. We are operating on the premise that in order to describe the future state of the nation's supply of states' parks, we must know where the supply has been, having incorporated the collective choices and mandates of public officials in guiding the states' parks and not necessarily the market demand and supply conditions. Our focus on production is ultimately an examination of the conversion of the factor inputs into visits by operators. Hence, we pose the following two research questions to direct our analyses:

Question 1 Which of the factor inputs to the nation's supply of states' parks contribute significantly to the production of outdoor recreation opportunities for public consumption?

Question 2 How productive have the states' operators of parks been in utilizing the potential capacities of the nation's supply over the past 27 years and what are the near term projections?

\subsection{The production process}

We can trace the study of the production of outdoor recreation by land-managers to early research by Seneca and Cicchetti (1969) where annual attendance was found to be a function of the parklands' characteristics. The authors adopted the production process concept for specifying what they referred to as a "user response model" to the 154 parks in the Appalachian Region. Similarly, we conceptualize the production process for a state's park system as creating the outputs of park visits from the input requirements of parklands, labor, and investment capital needed to meet the outdoor recreational needs and wants of the public where the technological changes in production are relatively infrequent. How well organized and skilled the state operator is at undertaking this transformation of the factor inputs into output will determine the operator's success in serving the public. In the private sector, this equates to the producer wanting to be as efficient as possible in transforming the inputs into output, while using the minimum level of inputs possible to achieve a set amount of output in order to reduce the extra cost of producing an extra unit of output (Nicholson, 2008). This action allows the producer to sell the outputs at a lower price in pursuit of the rational maximization of profits.

Our production equation is not a behavioral demand function for recreation trips necessitating the collection of visitors' travel distance sand cost measures from population zones to the states' parks and their associated substitutes. The equation explains and predicts the expected annual attendances over time to each state's park system $(x)$, a technical measure, in terms of the official reports of the quantities of factor inputs. We concisely conceptualize the production process with Equation (1),

$x=f(L, S, K)$.

The function $f(\cdot)$ describes the relationship between annual attendances and the different mixes of the following factor inputs:

$L=$ amount of labor required, $S=$ acres of parkland that comprise the land and water areas under management, and $K=$ capital expenditures and investments.

To satisfy the statistical assumptions for a normal distribution of the dependent variable and the removal of the statistical dependency in each case between the means and the variances of the factor inputs, Equation (1) takes a logarithmic form:

$x=\alpha L^{\beta_{1}} S^{\beta_{2}} K^{\beta_{3}}$.
The parameters $\beta_{1}, \beta_{2}$, and $\beta_{3}$ describe the contributions of the factor inputs to annual attendance. We are then able to calculate the states' utilization capacity rates with the post-estimation response residuals from Equation (2). We invoke the following assumptions in analyzing the production processes of the states' systems:

- Since any excess capacity of the recreation opportunities is lost due to their non-storability, the quantity of recreation opportunities consumed by the public is identical to the quantity of people visiting the park. A visit is the entry of any individual into a state's park for any length of time for recreation and/or education purposes consumed at the point of production (NASPD, 2010).

- The quantity of recreation visits, customarily reported as attendance by the states' parks operators, is not a behavioral measure like the quantity of trips from the estimation of recreation demand; rather attendance is a technical measure of the counts of the annual visits to a state's park system and does not imply the actual capacity of the system.

- Annual attendance has a constant average quality of services and, therefore, we do not directly consider quality differences here. We assume that the states' park operators had the authority to trade-off maintenance, enforcement, and visitor service as determined by the input requirements over time. Consequently, it is not possible to judge whether decreasing expenditures, changes in employment ratios, or changes in resource supply involved some sacrifice in service quality.

- In evaluating the model's parameters as to the scale of the 50 states' park operations, we cannot assume that a change in inputs necessarily results in a corresponding increase or decrease in park use regardless of the location of a state's system of parks as might be the case in the operations of a private firm. In theory, analysts assume that the production function is homogenous of degree one with the parameter values summing to one, thereby displaying a constant return to scale where the doubling of the use of inputs would lead to twice as much output.

\section{Research method}

The data for this longitudinal and cross-sectional analysis of panel data were obtained from the Annual Information Exchange (AIX), a database for the 50 states' park systems dating from 1984 (NASPD, 2010). The AIX compiles data from state-reported annual surveys related to states' park operations. We limited our analysis of the data to the annual observations from 1984 to 2010 and gave special care to include only the most complete data. In those instances where longitudinal data of interest were missing or seemed to be inaccurately recorded in the database, we interpolated and extrapolated the time series data to fill in the holes (StataCorp, 2009, [D] ipolate). The missing information was probably due to the incomplete self-recording of information by state contact personnel and/or previous data management issues in updating and handling the AIX archive itself. There was, of course, no guarantee of uniform market and labor prices across the 50 state park agencies.

\subsection{Output and factor inputs}

Attendance figures in the AIX database included the annual observations of the states' totals of both day use and overnight use. Over the previous 27 years, the 50 states' parks when taken together generated a mean annual attendance of $14.6 \mathrm{M}$ $(\mathrm{SD}=16.6 \mathrm{M})$. The distribution of the states' annual attendance was not symmetric around the mean and had a positive skew $\left(g_{1}=2.10\right)$ to the left of the mean, where $g_{1}$ represents the statistical concept of 
skewness in the sample's distribution or the sample's third central moment. The distribution reflected a higher concentration around the median of 8.4 million visits annually. However, the standard errors among the 50 states' systems varied little from a low of less than $1 \%$ for Pennsylvania to a high of $12 \%$ for Vermont.

State park labor, as provided by the AIX, referred to the number of state park personnel employed to maintain and effectively operate and protect parks. Labor included full-time, part-time, and seasonal workers. Parklands data was the total acreage of the areas in the states' park system, including water bodies, when the boundaries of the state park unit wholly enclosed the water body. Capital expenditures included the acquisition of land by cash or equivalent value (and not by other means) and periodic fixed capital expenditures for park construction and renovations. We concerned ourselves with the direct capital cost and not the foregone opportunity costs for the alternative use of parklands, because the states' park systems typically do not ascribe to the multiple-use doctrine of extracting valuable natural resources from parklands. We deflated the capital expenditures using the producer's price index, which tracks the average change in prices over time of domestically produced and consumed commodities and included the prices for capital equipment, but excluded prices for services (U.S. Department of Labor, 2010). We apportioned the capital expenditures equally between the current fiscal year and the forthcoming fiscal year. All the years were fiscal years (FY). The descriptive statistics for the output and factor inputs are displayed for each of the 50 states in Table 1.

\subsection{Statistical assumptions}

Prior to the specification of Equation (2), we addressed an important statistical assumption for the underlying short panel-data necessary to estimate the production equation by performing all the preliminary statistical tests with the statistical software components made available by StataCorp (2009, [XT]). The issue of particular concern was the heteroskedasticity across the 50 different park systems. In this case, heteroskedasticity referred to the statistical estimation phenomenon where the variances of the error terms in the user response equation did not remain constant among observations. Concerning Equation (2), the significant heteroskedasticity from a preliminary test of the panel-data was attributable to the cross-sectional differences in annual attendance [LR $\chi^{2}(49)=1008$ ] (Wiggins and Poi, 2003). The data incorporated a wide variety of unobservable actions and decisions taken by state officials in providing outdoor recreation opportunities. For example, the states' park system budgets were not set through regional planning commissions or coordinated efforts. In fact, the states' have adopted various land-management orientations toward either the preservation of public lands or recreation development, typically bound by past legislative actions and directives (Davis, 2008). However, it was plausible that states' parks agencies may under-invest in recreation facilities and their continuing operations if the adjacent states were perceived by visitors to offer outdoor recreation opportunities of higher quality. The logic of this "spillover effect" was that state policy-makers would be less likely to invest in their own outdoor recreation services if adjacent states have a high level of financial commitment to the provision of those services (Grandy, 2009). This effect might be especially notable in the eastern United States where interstate travel is less of a barrier to recreation participation. In the east, this scenario might be a valid option for state agencies to conserve their own fiscal resources and still have their constituents' outdoor recreation needs met. An examination of the literature also found other plausible reasons to account for the cross-sectional differences or heteroskedasticity. These included distributional equity issues involving the dispersed geographical locations,
Table 1

Means for annual attendance and factor inputs from 1984 to 2010 by states $(N=1350)$.

\begin{tabular}{|c|c|c|c|c|}
\hline State & Attendance $^{\mathrm{a}}$ & Labor & Parkland & Capital \\
\hline Alabama & $5,493,965$ & 859 & 49,110 & $6,819,932$ \\
\hline Alaska & $4,852,201$ & 172 & $3,271,861$ & $3,969,762$ \\
\hline Arizona & $2,359,193$ & 297 & 50,425 & $7,000,342$ \\
\hline Arkansas & $7,509,594$ & 1018 & 50,081 & $14,560,045$ \\
\hline California & $76,359,445$ & 4196 & $1,394,007$ & $56,639,661$ \\
\hline Colorado & $10,391,111$ & 825 & 333,434 & $18,039,089$ \\
\hline Connecticut & $7,570,127$ & 724 & 185,792 & $11,458,443$ \\
\hline Delaware & $3,500,254$ & 579 & 18,801 & $17,865,147$ \\
\hline Florida & $15,628,629$ & 1378 & 508,575 & $29,308,913$ \\
\hline Georgia & $13,440,703$ & 1143 & 71,706 & $15,416,968$ \\
\hline Hawaii & $13,444,848$ & 137 & 26,777 & $5,448,095$ \\
\hline Idaho & $2,673,667$ & 334 & 42,696 & $4,565,117$ \\
\hline Illinois & $38,646,936$ & 960 & 401,806 & $37,292,564$ \\
\hline Indiana & $14,200,255$ & 1585 & 132,781 & $6,016,083$ \\
\hline Iowa & $13,114,233$ & 342 & 80,716 & $7,718,041$ \\
\hline Kansas & $6,300,674$ & 273 & 77,477 & $3,370,636$ \\
\hline Kentucky & $14,460,928$ & 2464 & 47,473 & $20,792,654$ \\
\hline Louisiana & $1,510,083$ & 454 & 39,214 & $13,037,864$ \\
\hline Maine & $2,234,887$ & 308 & 141,232 & $2,256,681$ \\
\hline Maryland & $9,531,332$ & 1035 & 231,457 & $17,486,686$ \\
\hline Massachusetts & $15,755,977$ & 1736 & 293,838 & $23,898,461$ \\
\hline Michigan & $23,460,564$ & 1459 & 275,126 & $9,481,303$ \\
\hline Minnesota & $7,671,846$ & 735 & 240,321 & $7,686,871$ \\
\hline Mississippi & $3,721,476$ & 464 & 23,237 & $1,977,922$ \\
\hline Missouri & $15,498,519$ & 816 & 143,958 & $9,503,766$ \\
\hline Montana & $3,114,627$ & 197 & 53,673 & $2,264,019$ \\
\hline Nebraska & $10,013,894$ & 891 & 141,246 & $3,220,423$ \\
\hline Nevada & $3,164,004$ & 214 & 140,059 & $3,120,551$ \\
\hline New Hampshire & $3,173,994$ & 512 & 120,303 & $3,319,251$ \\
\hline New Jersey & $13,475,682$ & 1016 & 347,988 & $15,149,352$ \\
\hline New Mexico & $4,628,224$ & 250 & 102,278 & $5,248,851$ \\
\hline New York & $55,382,560$ & 6520 & 737,173 & $44,996,295$ \\
\hline North Carolina & $10,925,521$ & 657 & 155,745 & $19,135,576$ \\
\hline North Dakota & $1,012,072$ & 178 & 18,789 & $1,457,266$ \\
\hline Ohio & $57,659,925$ & 1531 & 187,738 & $18,636,216$ \\
\hline Oklahoma & $15,169,436$ & 909 & 76,400 & $4,699,753$ \\
\hline Oregon & $40,329,750$ & 665 & 93,972 & $7,223,540$ \\
\hline Pennsylvania & $36,231,314$ & 1671 & 284,447 & $21,729,307$ \\
\hline Rhode Island & $5,336,860$ & 469 & 8868 & $5,482,415$ \\
\hline South Carolina & $8,428,177$ & 848 & 81,026 & $6,648,481$ \\
\hline South Dakota & $6,814,484$ & 484 & 98,019 & $4,560,350$ \\
\hline Tennessee & $27,224,007$ & 1632 & 148,615 & $13,528,336$ \\
\hline Texas & $17,928,297$ & 1223 & 521,524 & $17,069,503$ \\
\hline Utah & $5,461,241$ & 324 & 117,706 & $7,087,707$ \\
\hline Vermont & 925,426 & 326 & 80,508 & $1,450,357$ \\
\hline Virginia & $5,086,792$ & 743 & 68,383 & $14,164,289$ \\
\hline Washington & $44,878,216$ & 893 & 224,243 & $22,414,631$ \\
\hline West Virginia & $8,216,930$ & 1299 & 191,786 & $4,520,558$ \\
\hline Wisconsin & $13,472,853$ & 620 & 134,253 & $8,654,170$ \\
\hline Wyoming & $2,236,791$ & 165 & 120,576 & $3,252,830$ \\
\hline
\end{tabular}

${ }^{a}$ Notes. Attendances are annual counts of visitors to the state's parks. Labor is the number of reported workers. Parkland is total area in acres and capital investment is in dollars. We deflate the capital investment with the producer's price index, which tracks the average change in prices over time of domestically produced and consumed commodities and includes the prices for capital equipment, but excludes prices for services (Bureau of Labor Statistics, 2010). We apportion capital expenditures equally between the current fiscal year reported and the forthcoming fiscal year.

efficiencies of the existing operators along the long-run cost curve, and restrictions on permissible state debt levels. Moreover, in many states the lack of competitors in their service areas create different types of market behaviors and pricing practices that lead states' officials to undertake dissimilar operating and spending decisions (Loomis and Walsh, 1997). In addressing the issue of heteroskedasticity, we failed to reject the Wooldridge test for the null hypothesis of no first-order (serial) autocorrelation in the panels (Wiggins and Poi, 2003). The results from this test of temporal autocorrelation suggested that although present in the data $[F(1,49)=4.77]$, the amount of autocorrelation was not statistically significant at the 0.01 level. 


\subsection{Data analysis}

For theoretical reasons we specified Equation (2) to follow a non-linear process and to ensure our analysis:

- avoided the implied non-normality of the error distributions and the left-truncation of the error disturbances of the dependent variables;

- obtained estimates that were of a better fit to the AIX data; and

- provided a convenient reporting of the point elasticities of the independent variables from the statistical estimation.

With respect to the third point, elasticity indicated the percentage change in the dependent variable resulting from a one percentage change in the independent variables. In this case, the change in the dependent variable could be less than, greater than, or proportional to the change in the independent variables depending on whether the elasticity was less than, greater than, or equal to unity.

Annual attendance was a non-negative integer count and generated by a Poisson-like process, except that the amount of variation in the attendance counts was greater than the conditional mean expected of a true Poisson distribution. This excess amount of variation accounted for the over dispersion in the attendance counts. Our approach was to treat the violation of this assumption as a nuisance and correct it by subjecting the balanced, short paneldata to the recommended procedures for the estimation of a Poisson process and over dispersion (Egan and Herriges, 2006) with the negative binomial regression (Hilbe, 2008). The negative binomial regression processed a Poisson model with a gamma distributed error term for the counts of the annual attendances, allowed for the systematic and random variations in the counts across states, and addressed the over dispersion in the counts. The short panel, which consisted of 50 states' systems and 27 years, required a fixed-effects estimator (Cameron and Trivedi, 2009, p. 258). However, Hilbe (2008, p. 207) and others have called the negative binomial fixedeffects estimator into question. The conditional maximum likelihood approach failed in controlling all of its predictors and, when conditioned out of the log-likelihood, the dispersion parameter did not correspond to the different intercepts in decomposing the attendance counts. Therefore, we adopted a cross-sectional unconditional estimator along with clustered-robust standard errors. The general linear model framework was optimal for a nonlinear regression modeling the intrinsic heteroskedasticity and robust to the presence of serial correlation, as was the case with the states' parks data in this study (Cameron and Trivedi, 2009, p. 327).

The predicted counts of the annual attendances $\left(x_{i t}\right)$ for $i=1 \ldots .50$ states' systems and $t=1 . .27$ years of panel-data were the sum of the independent variables and the unobserved heterogeneity among the counts with theta $\left(\theta_{i}\right)$. We estimated the parameters ( $\beta$ 's) for the factor inputs with Equation (3) for ith state's park system:

$\ln \left[x_{i t}\right]=\alpha+\beta_{1} \ln L_{i t}+\beta_{2} \ln S_{i t}+\beta_{3} \ln K_{i t}+\theta_{i}$.

In keeping the exposition simple, we suppressed the state $i$ and year $t$ subscripts in showing the commonly observed form of this negative binomial probability density function (Hilbe, 2008, p. 80),

$\frac{\Gamma\left(x+\frac{1}{\alpha}\right)}{\Gamma(x+1) \Gamma\left(\frac{1}{\alpha}\right)}\left(\frac{1}{1+\alpha \mu}\right)^{\frac{1}{\alpha}}\left(\frac{\alpha \mu}{1+\alpha \mu}\right)^{x}$.

The rate $\mu$ in Equation (4) consisted of both the deterministic and random components of the production equation that determined the attendance counts. Since we assumed that the unobserved effects that would not otherwise be accounted for in a Poisson process were distributed gamma $(\Gamma)$ with a mean of one and variance of alpha $(\alpha)$, the counts approximated the gamma function, $\Gamma(1 / \alpha, \alpha) .{ }^{1}$ Equation (4) re-expressed in terms of the log-likelihood $(L)$ was from Hilbe (2008, p. 83):

$$
\begin{aligned}
L(\mu ; x, \alpha)= & \sum \exp \{x \ln (a \mu) /(1+\alpha \mu)-(1 / \alpha) \ln (1+\alpha \mu) \\
& +\ln \Gamma(x+1 / \alpha)-\ln \Gamma(x+1)-\ln \Gamma(1 / \alpha)\} .
\end{aligned}
$$

The estimation process was iterative with the log-likelihood function updating the information matrix, which the software calculated as the second derivative of the likelihood function, on successive iterations until the algorithm in Equation (5) converged. The generalized linear model with the appropriate clustering option for the 50 states made the necessary adjustment to the diagonal matrix of the error term and all the coefficients were heteroskedasticity, consistent with the robust error structure corrected for autocorrelations within the panels (StataCorp, 2009, [R], glm). We stipulated that the expectation and iterated maximization (eim) algorithm alternate between the conditional expectation and maximization steps in the estimation process to effectively exploit the inherent statistical structure of the parameters in the estimations. Ultimately, the underlying goal of the estimation process involved the maximization of the likelihood score function in order to estimate parameter values. Standard errors obtained from the information matrix determined which parameters made the attendance counts most likely and quantified the effects of the factor inputs on the attendance counts (Wooldridge, 2002). The general linear model in the presence of heteroskedasticity was unbiased and consistent with a count-data process. Following the general linear estimation process, the post-estimation prediction of the expected annual attendance introduced the coefficients to the normal random values of the factor inputs in Equation (3).

\section{Results and discussion}

With the conceptual problems explained and the production equation specified, we display the results from the general linear estimation process in Table 2. A means of judging the adequacy of the statistical outcome was to compare the predicted counts of the annual attendances to those reported. Overall, the fit of the Equation (3) to the cross-sectional count-data was good given the (heteroskedastic) structure of the reported data for the 50 states' governments, with the pseudo $R^{2}$ explaining 0.56 percent of the variance on a 0 to 1 scale. Furthermore, a visual examination of the deviance residuals plotted against the fitted values, as recommended by Wooldridge (2002) for examining the goodness of fit of the general linear model having the best properties, found the deviance residuals to be approximately normally distributed $\left(g_{1}=<1.0\right)$ suggesting the model was correct.

The coefficients reported in column 2 corresponded to the point elasticities in relating the $1 \%$ increases (or decreases) in the factor inputs to an increase (or decrease) in annual attendance, the dependent variable. The elasticities in columns 4 and 5 were at the $95 \%$ confidence interval. The labor, parkland, and capital coefficients were positive and inelastic with respect to the counts of annual attendances. This meant that the attendances would increase proportionately less than with the percentage increases in

\footnotetext{
1 This mathematical function generalizes the notion of a factorial and must have positive real input values (Hilbe, 2008). The gamma curve results if we take a population having the exponential distribution with mean one, obtain many samples of size $\alpha$, and calculate the sum of the elements in each sample. The resulting exponential curve with a mean of one is simply a special case of the gamma curve with $\alpha=1$. As the magnitude of $\alpha$ increases, the gamma curve moves to the right and the distribution spreads out.
} 
Table 2

Production equation results for the counts of annual attendance to the 50 states' park systems.

\begin{tabular}{lllll}
\hline Factor input & Coefficient $^{\mathrm{a}}$ & $z$-value & 95\% CI & \\
\hline Labor & 0.546 & 19.610 & 0.491 & 0.600 \\
Parkland & 0.205 & 10.250 & 0.166 & 0.244 \\
Capital & 0.060 & 3.360 & 0.025 & 0.095 \\
Constant & 9.390 & 35.200 & 8.866 & 9.912
\end{tabular}

Summary Statistics

$N=1350 ;$ Log-likelihood $=-23,152$; pseudo $R^{2}=0.56$; Negative binomial parameter, $\alpha=0.54$

${ }^{a}$ Notes. Coefficients and standard errors are logarithms (ln). The $z$-test result is an asymptotic (i.e., large sample) measure of statistical significance of the input coefficient. Hilbe (2008) derives the negative binomial regression from the Poisson regression with the specification of the outcome characterized by gamma heterogeneity. The parameter alpha $(\alpha)$ is a measure of the over dispersion in attendance counts around the conditional mean. The resulting value of 0.54 indicates a relatively high degree of over dispersion, meaning that the conditional mean is not equal to the conditional variance in the data in meeting the assumption of the Poisson regression. The pseudo $R^{2}$ is a measure of the goodness of fit of the count-data estimates to the reported attendance counts by states. The expected annual attendance was $14.3 \mathrm{M}$ visits per year where the mean measured the center of the conditional distribution for the counts of the annual attendances.

b All $z$-values were significant at the $p<0.01$ level.

the numbers of workers, acres of parklands, or capital investments in the states' parks. Labor had the greatest statistically significant influence on attendance, with each $1.00 \%$ increase in the labor force equating to an increase of $0.54 \%$ in attendance. This was approximately 2.5 greater than the $0.21 \%$ for parklands on attendance. We were in fact $95 \%$ confident that for every $1.00 \%$ increase (decrease) in labor, services would increase (decrease) between $0.49 \%$ and $0.60 \%$. Capital investment in the states' park had the least significant influence on attendance with a $0.06 \%$ increase in attendance for every $1 \%$ of capital expenditures.

In applying production theory to the nation's supply of states' parks, we were aware of the assumption as commonly applied in the case of a private producer (e.g., hospital) that the results should be homogenous of degree one, which meant the input factor coefficients sum to unity or the constant returns to scale. The sum of the coefficients in Table 2 had an order of homogeneity of 0.81 , which is less than unity. Consequently, the production and subsequent consumption of outdoor recreation increased by less than the proportional changes in the factor inputs, exhibiting decreasing returns to scale.

The business argument favoring the constant returns to scale, as opposed to decreasing in this case, is conceptual in arguing that if parks' operators simply duplicate the economic environment they should get twice the attendance (Holtz-Eakin, 1992). Although reported here, the degree to which the constant returns to scale argument is a reasonable assumption to the nation's supply of states' parks is an empirical question, in our opinion, when given the nonmarket nature and varying political actions influencing the 50 states' production processes.

\subsection{Capacity utilization of the states' parks}

In answering the research questions and discussing results, we begin by exploring the utilization of the 50 states' systems that may have been possible (Berndt and Morrison, 1981). We do so in light of the capacity utilization rate that expresses the ratio of the response residual in the numerator to the predicted attendance for each of the states' systems in the denominator from the post-estimation results (Hardin and Hilbe, 2007, p. 53) as,

$\frac{x_{i t}^{R}=\left(x_{i t}-\hat{x}_{i t}\right)}{\hat{x}_{i t}+1}$
By adding a constant of one to the utilization rate, we set the capacity utilization rate to the full capacity rate of one (100\%) where the predicted attendance for a state's system equals the officially reported amount. At the existing level of production, we could therefore deema state's system as either:

- operating above one with an over-capacity in exceeding the expected annual attendance;

- operating equal to one at full capacity; or

- operating below one with an excess capacity relative to the expected annual attendance.

We provide the cross-sectional capacity utilization rates $x_{i t}^{R} / s$ for FY2010, the most current data, in Table 3. In column 2, for example, the utilization rate estimate of Alabama's state parks is 0.32 or $32 \%$ of its potential capacity (i.e., 100\%); next, Alaska is 0.52 or $52 \%$ of its potential capacity; and so forth down column 2 .With the aid of the rankings in column 3, we identify the five states with the greatest over-capacity utilizations as Oregon (3.33), Hawaii (2.92), Ohio (2.49), Washington (2.82), and Illinois (2.31), and the five with the smallest capacity utilizations as Vermont (0.11), Louisiana (0.20), North Dakota (0.31), Maine (0.38), and Arizona (0.38).

\subsection{Time-varying rates of capacity utilizations}

The annual mean of the capacity utilization rates for the $i=1 \ldots .50$ states' systems and for each of the $t=1 \ldots .27$ fiscal years is $\bar{x}_{T}^{R}=\frac{1}{50} \sum_{i=1}^{50} x_{i t}^{R}$

By uncovering the historical pattern in the annual mean utilizations, nationwide operators met or exceed the capacity utilization expectations from FY 1984 through FY1990 (Table 5, column 2). However, beginning in FY 1991, the mean utilization rate for the nation's supply of states' parks signaled a trend toward excess capacity utilization. That trend continued through FY 2010. Evidently, during this period, the operators experienced scale diseconomies having the potential to expand production by $1-20 \%$ over the reported annual attendances. We know from the general linear modeling results that the production of outdoor recreation is sensitive to the specification of the factor inputs with labor having the greatest significant influence. Apparently, operators did not meet their potential annual attendances through varying labor along with the other factor inputs in all instances. A common technical explanation is that the public sector operators, unlike private producers, find themselves restricted in their substitution possibilities between capital and labor. The restriction stems from the consistently small capital-labor ratio (0.11) for the states' park systems and other financial constraints operators face like the need to obtain legislative approvals for needed capital investments. In all likelihood, the states' reports of the FY operational results to the AIX encompass the financial constraints and operators' reactions to exogenous influences on the parks' production processes. Such influences as environmental disasters (e.g., hurricanes), political uncertainties, and economic shocks to a state's economy, all of which may have altered the sizes of the legislative appropriations for the factor inputs from one year to the next, can cause production efforts to vary.

Of primary concern to us is projecting the national trend in capacity utilization into the near future. Evidently, the decline in the annual mean rates increases from an $80 \%$ utilization to $93 \%$ since FY 2008, with the states' operators becoming more productive in meeting the excess capacity while controlling the factor inputs at the means. Determining if this trend is likely to continue requires us to perform a unit root test in deciding if the trending 
Table 3

Cross-sectional capacity utilization rates by state park system for FY 2010 $(N=1350)$.

\begin{tabular}{|c|c|c|}
\hline State & Rate $^{\mathrm{a}}$ & Rank \\
\hline Alabama ${ }^{\text {b, c }}$ & 0.32 & 44 \\
\hline Alaska & 0.52 & 33 \\
\hline Arizona & 0.38 & 41 \\
\hline Arkansas ${ }^{b}$ & 0.57 & 31 \\
\hline California $^{\mathrm{b}, \mathrm{c}}$ & 1.01 & 14 \\
\hline Colorado $^{c}$ & 0.74 & 21 \\
\hline Connecticut & 0.69 & 26 \\
\hline Delaware $^{\mathrm{b}, \mathrm{c}}$ & 0.51 & 34 \\
\hline Florida & 0.70 & 24 \\
\hline Georgiab, c $^{\text {b }}$ & 0.67 & 27 \\
\hline Hawaiic & 2.92 & 2 \\
\hline Idaho & 0.61 & 29 \\
\hline Illinois ${ }^{b, c}$ & 2.31 & 5 \\
\hline Indiana $^{\mathrm{b}, \mathrm{c}}$ & 0.58 & 30 \\
\hline Iowa ${ }^{c}$ & 2.25 & 6 \\
\hline Kansas $^{\mathrm{b}}$ & 1.55 & 8 \\
\hline Kentucky ${ }^{\text {b, c }}$ & 0.41 & 39 \\
\hline Louisiana $^{\mathrm{b}}$ & 0.20 & 48 \\
\hline Maine $^{\mathrm{c}}$ & 0.38 & 40 \\
\hline Maryland $^{\mathrm{c}}$ & 0.70 & 25 \\
\hline Massachusetts ${ }^{\mathrm{c}}$ & 1.39 & 10 \\
\hline Michigan $^{c}$ & 0.89 & 17 \\
\hline Minnesota $^{c}$ & 0.50 & 35 \\
\hline Mississippi ${ }^{\text {b }}$ & 0.20 & 47 \\
\hline Missouri ${ }^{\mathrm{b}, \mathrm{c}}$ & 1.28 & 11 \\
\hline Montana & 0.36 & 43 \\
\hline Nebraska & 0.82 & 20 \\
\hline Nevadab & 0.46 & 38 \\
\hline New Hampshire & 0.14 & 49 \\
\hline New Jersey ${ }^{c}$ & 0.83 & 18 \\
\hline New Mexico & 0.66 & 28 \\
\hline New York ${ }^{\mathrm{b}, \mathrm{c}}$ & 0.73 & 22 \\
\hline North Carolina ${ }^{\mathrm{b}, \mathrm{c}}$ & 1.00 & 16 \\
\hline North Dakota & 0.31 & 46 \\
\hline Ohio ${ }^{\text {b, c }}$ & 2.49 & 4 \\
\hline Oklahoma $^{\text {b }}$ & 1.01 & 15 \\
\hline Oregon & 3.33 & 1 \\
\hline Pennsylvania $^{\mathrm{c}}$ & 1.78 & 7 \\
\hline Rhode Island ${ }^{\mathrm{b}}$ & 1.05 & 13 \\
\hline South Carolina ${ }^{\mathrm{b}, \mathrm{c}}$ & 0.82 & 19 \\
\hline South Dakota ${ }^{\mathrm{b}}$ & 0.71 & 23 \\
\hline Tennessee $^{b, c}$ & 1.43 & 9 \\
\hline Texas $^{\mathrm{b}}$ & 0.32 & 45 \\
\hline Utah & 0.53 & 32 \\
\hline Vermont & 0.11 & 50 \\
\hline Virginia $^{\text {b, c }}$ & 0.48 & 36 \\
\hline Washington & 2.82 & 3 \\
\hline West Virginia ${ }^{b}$ & 0.37 & 42 \\
\hline Wisconsin ${ }^{c}$ & 1.23 & 12 \\
\hline Wyoming ${ }^{\mathrm{b}}$ & 0.47 & 37 \\
\hline
\end{tabular}

${ }^{a}$ Notes. We display the capacity utilization of the states' park systems for 2010 , the most current data, while controlling for levels of factor inputs at the means. A value greater than one indicates the state exceeded the capacity utilization expectation (over-capacity), a value of one means the state met the utilization expectation or full capacity (100\%), and a value of less than one means the system had excess capacity not met at the existing production level. The state rankings are in descending order in column 3.

b States ranks in the top $50 \%$ for a recreation orientation by the state's officials in the management of public-lands. The criteria for judging a state' recreation orientation relate to the amount of recreation facilities and the percentage of a state's parklands (Davis, 2008, p. 53).

c States that rank in the top $50 \%$ for a preservation orientation in terms of the management of their park system. The criteria for judging a preservation orientation refers to the amounts and designations of natural areas, wilderness, and wildlife management areas (Davis, 2008, p. 52).

series should be first differenced or simply regressed over time to render the data stationary, which is a necessary condition for stable coefficients in the forecast analysis. Wooldridge (2002, p. 804) describes the unit root process as a high persistent time series where the current value equals the last period's value, plus a weakly dependent disturbance. Applying the finding of an augmented Dickey-Fuller unit root test $[Z(t)=-3.428, p=0.01]$ to the series, the utilization rates were stationary over the 27 years. Given the $p$-value was less than 0.05 level of statistical significance; we rejected the null hypothesis that the rates exhibited a unit root. We instead accepted the alternative hypothesis that a stationary process generated the rates where the joint distributions of the variable were invariant across time and the time series need not be differenced (StataCorp, 2009, [TS], dfuller).

We applied an autoregressive model of the first-order or simply the forecasting equation to the time series of the mean capacity utilization rates, $\bar{x}_{T}^{R} / S$ (Wooldridge, 2002). We specified autocorrelation-consistent variance estimates for the standard errors in the statistical software for the linear regression routine (StataCorp, 2009, [R] reg). The forecasting equation generated annual forecasts by extrapolating past sequences of movements in the time series into the future without explaining the underlying conditions or the patterns of movements in the series. This allowed us to estimate the coefficients that described the consecutive values of the annual series from the specified, time-lagged (previous) rate as,

$$
\hat{x}_{T}^{R}=c+\rho_{1}\left(x_{t-1}^{R}\right), \ldots, \rho_{n}\left(x_{t-n}^{R}\right)+\varepsilon_{t} .
$$

The error term, $\varepsilon_{t}$, was equal to $\sigma^{2}$ and serially uncorrelated, the parameters were $\rho$, and the constant $c$ represented the intercept because of lagged rates in the equation. The estimation of Equation (6) with regression analysis was relatively straightforward, statistically significant $[F(1,24)=179.66$; MSE $=0.05]$, and yielded an $R^{2}$ of 0.86 (Table 4 ).

Determining the appropriate length of the time-lagged variable on right-hand side of the forecasting equation involved visually checking a graph of the partial autocorrelations (StataCorp, 2009, [T], corrgram). As each of the successive autocorrelation functions tapered off gradually, we were then able to identifying at which lag length the cut-off point occurred in the partial autocorrelations. This approach resulted in the parsimonious parameterization of the forecasting equation and a lag length of one fiscal year (Table 4). In order to forecast the annual utilization rates over the short-term, FY 2011 to FY 2013, we introduced the lagged coefficient, constant, and input data into Equation (6) to make the year-ahead forecasts. By letting $x_{t}^{R}$ denote FY 2010, we let the one-period ahead forecast value be $\hat{x}_{t+1}^{R}$ and the $i$ th period ahead forecast be $\hat{x}_{t+i}^{R}$ for $i=1-3$ until we achieved the three year forecast, as shown in Table 5.

For the next two years at least, we forecast a relatively flat trend in the series of mean capacity utilization rates of approximately $93 \%$ $(\mathrm{SE}=0.012$ ) for the states' park systems. We are in turn $95 \%$ confident in our outlook for the next three years that the mean rate will vary between $90 \%$ and $95 \%$ utilization level with an excess capacity of $10-5 \%$.

\subsection{Public-lands management orientations}

We earlier speculated the orientations of the states' park systems and their officials might play an important role in guiding the on-

Table 4

Forecast equation results for nationwide annual mean utilization rates ${ }^{\mathrm{a}}$.

\begin{tabular}{lllr}
\hline Utilization rate $\left(\bar{x}_{T}^{R}\right)$ & Coefficient & SE & $t$-value \\
\hline$x_{t-1}^{R}$ & 0.781 & 0.058 & 13.400 \\
Constant & 0.201 & 0.055 & 3.630 \\
\hline
\end{tabular}

a Notes. The annual mean utilization rate for the $t=1 \ldots 27$ fiscal years or FY 1984 to FY 2010is $\bar{x}_{T}^{R}=(1 / 50) \times\left(\sum_{i=1}^{50} x_{i t}^{R}\right)$. Since there is a coefficient in the model for the lagged rate, the constant represents the intercept. The $R^{2}$ was 0.86 which is a measure of the goodness-of-fit of the forecast model to the rate series. The regression model is statistically significant at the $p>\chi^{2}=0.000$ levels $[F(1,24)=179.66$; MSE $=0.05]$. All the coefficients have t-values with a $p>\mid t$-value $\mid$ at less than the 0.01 level of statistically significance. 
Table 5

Nationwide past annual mean utilization rates and forecasts in bold italics.

\begin{tabular}{ll}
\hline Fiscal year & Rate \\
\hline 1984 & 1.42 \\
1985 & 1.30 \\
1986 & 1.26 \\
1987 & 1.17 \\
1988 & 1.16 \\
1989 & 1.12 \\
1990 & 1.14 \\
1991 & 0.93 \\
1992 & 0.98 \\
1993 & 0.95 \\
1994 & 0.99 \\
1995 & 1.03 \\
1996 & 0.96 \\
1997 & 0.95 \\
1998 & 0.97 \\
1999 & 0.97 \\
2000 & 0.96 \\
2001 & 0.96 \\
2002 & 0.88 \\
2003 & 0.87 \\
2004 & 0.88 \\
2005 & 0.86 \\
2006 & 0.85 \\
2007 & 0.83 \\
2008 & 0.80 \\
2009 & 0.86 \\
2010 & 0.93 \\
$\mathbf{2 0 1 1}$ & $\mathbf{0 . 9 3}$ \\
$\mathbf{2 0 1 3}$ & $\mathbf{0 . 9 3}$ \\
\hline & $\mathbf{0 . 9 2}$ \\
\hline
\end{tabular}

going and future production of outdoor recreation. The five criteria for judging a preservation orientation relate to the amounts of natural areas designated as natural areas, wilderness, or wildlife management areas (Davis, 2008, p. 52). The three criteria for judging a state's recreation orientation refer to the number of recreation facilities and the percentage of state parkland (p. 53). Since Davis's rankings of the preservation and recreation orientations are invariant over time (limited only to 2008, the year Davis reports the findings) we created two indicator variables where we assigned the value of one to states in the top 25 rankings and zero otherwise. We identified the top 25 states in the rankings of the recreation and preservation orientations by the state's officials in the management of public-lands with superscripts in Table 3, column 1.

Next, we tested the Spearman non-parametric associations with the FY 2010 capacity utilization rates for the 50 states' systems and the rankings of states' orientations from Davis's 2008 study. Evidently, the quantity of added facilities to broaden parks' appeal to the public (i.e., a recreation orientation) is not important in explaining the FY 2010 utilization capacities of the states' systems $\left(r_{\mathrm{S}}=-0.08, p>|t|=0.58\right)$. In failing to reject the null hypothesis of independence, we view a system's effort in producing outdoor recreation as being independent of the states' orientations toward providing passive and active recreation opportunities to the public for the purposes of bolstering economic development and tourism. Alternatively, we reject the null hypothesis that the current capacity is independent of a preservation-oriented focus $\left(r_{\mathrm{S}}=0.36\right.$, $p>|\mathrm{t}|=0.00$ ). In fact, those states' systems experiencing an overcapacity in park utilizations are $36 \%$ more likely to be associated with a state's park system being oriented toward public-lands preservation. If the primary objective of a state's park system is to increase attendance, our results presented here for FY 2010 would suggest that the states' officials continue focusing on the preservation and protection of the native ecosystems, natural landscapes, and biodiversity in general. Our recommendation is that the states' officials responsible for managing the parks in the preservationoriented states continue to emphasize their focus on the preservation of public-lands, even as their legislators continue to wrestle with difficult distributional equity decisions regarding maintaining minimum costs and revenue self-sufficiency in funding their states' future recreation needs.

\section{Conclusion}

Irrespective of public-lands use orientations by public officials, the states' parks operators will continue to contend with the need to increase revenues from services in their struggles with ever increasing state funding liabilities and deficits (Nelson A. Rockefeller Institute of Government, 2010). Even so, states' park operators are still better off in the long-term in producing additional outdoor recreation opportunities. In our view, the public will continue to accept the current cost structures for the continued operations of the states' parks on the compelling distributional equity issues and tax efficiency grounds when taking into consideration their states' public-land management orientations.

What we derive from the production analysis, and in particular the significance of the labor coefficient, is that state governments will experience a perpetual need for more labor to maintain their parklands if attendance is to increases in the future and not necessarily more capital spending. If not, the resulting economic impacts on the parks' operators will force states into adjusting their production processes by varying their average qualities of area maintenance, enforcement, and visitor services. States might consider increasing the prices charged to visitors for the rentals of facilities and services when addressing the state revenue shortfalls in tax collections.

Since 1990, the national supply of the states' park systems has been under-utilized in relation the potential capacity. Regarding the future, we forecast $90-95 \%$ capacity utilization by the public at FY 2010 levels of factor inputs. In FY 2010, the total national expenditure for the 50 states' park systems was $\$ 2309 \mathrm{M}$. This reflects the amount of income that the public is willing to sacrifice to assure that states' parks are available to them. We can then only assume that the public finds this level of expenditure to be equitable. To put this figure in perspective, the states' governments provided $\$ 79,694 \mathrm{M}$ to subsidize local governments for primary and secondary education in 2007 (U.S. Department of Commerce, 2010). This is approximately 27 times greater than the amount provided for the state's park systems. Regardless of their lower priority relative to public education, we speculate that citizens in the United States value their states' parks highly and will continue to in the future.

\section{References}

Berndt, E., Morrison, J., 1981. Capacity utilization measures: underlying economic theory and an alternative approach. American Economic Review 71, 48-52.

Cameron, C., Trivedi, P., 2009. Microeconomics Using Stata. StataCorp LP, College Station, TX.

Davis, S., 2008. Preservation, resource extraction, and recreation on public lands: a view from the states. Natural Resources Journal 48, 303-352.

Egan, K., Herriges, J., 2006. Multivariate count data regression models with individual panel data from an on-site sample samples. Journal of Environmental Economics and Management 52 (2), 567-581.

Grandy, C., 2009. The "efficient" public administrator: pareto and a well-rounded approach to public administration. Public Administration Review 69 (6), 1115-1123.

Hardin, J.W., Hilbe, J., 2007. Generalized Linear Models and Extensions. A Stata Press Publication, StataCorp LP, College Station, TX.

Hilbe, J., 2008. Negative Binomial Regression. Cambridge University Press, New York.

Holtz-Eakin, D., July 1992. Public-sector Capital and Productivity Puzzle (Working Paper No. 4122). National Bureau of Economic Research.

Landrum, N., 2004. The State Park Movement. University of Missouri Press, Columbia, MO.

Loomis, J., Walsh, R., 1997. Recreation Economic Decisions: Comparing Benefits and Costs, second ed. Venture Publishing, State College, PA. 
NASPD, 2010. AIX, Annual Information Exchange [Data File, 1985-2010], and Reports. The National Association of State Park Directors, Raleigh, NC.

Nelson A. Rockefeller Institute of Government, 2010. Retrieved from: http://www. rockinst.org/government_finance/.

Newcomer, K.E., 2007. Measuring government performance. International Journal of Public Administration 30 (3), 307-329.

Nicholson, W., 2008. Micro-economic Theory: Basic Principles and Extensions. The Dryden Press, Hinsdale, IL.

Phaneuf, D., Smith, V., 2004. Recreation demand models. In: K. Maler, J. Vincent (Eds.) Handbook of Environmental Economics (Chapter 13), North Holland.

Seneca, J., Cicchetti, C., 1969. User response in outdoor recreation: a production analysis. Journal of Leisure Research 1 (3), 238-246.

Siderelis, C., Moore, R., 2009. State government provision of excludable outdoor recreation opportunities: the influences of fees and charges on state park attendance. Unpublished manuscript, The National Association of State Parks Directors, Raleigh, NC.
Siderelis, C., Leung, Y., Attarian, A., 2011. National Association of State Park Director's Report: FY 2011 - FY 2014 Outlook. National Association of State Park Directors, Raleigh, NC.

StataCorp, 2009. Stata Statistical Software: Release 11. StataCorp LP, College Station, TX Strauss, C., 1975. A financial management study for Pennsylvania parks. Trends (July-September), 44-48.

U. S. Department of Commerce, Bureau of the Census. State Government Finances. accessed on 12.10 .09 at. http://www.census.gov/govs/estimate/.

U.S. Department of Labor, Bureau of Labor Statistics, 2010. PPI Databases. http:// www.bls.gov/ppi/\#tables.

Walls, M., Darley, S., Sikamaki, J., 2009. State of the Great Outdoors: America's Parks, Public Lands, and Recreation Resources. Resources for the Future, Washington DC

Wiggins, V., Poi, B., 2003. Testing for panel-level heteroskedasticity and autocorrelation. Retrieved from. http://www.stata.com/support/faqs/stat/panel.html.

Wooldridge, J., 2002. Econometric Analysis of Cross Section and Panel Data. MIT Press, Cambridge, MA. 